\title{
ISOZYMIC ANALYSIS OF ESTERASES IN MATURE SEEDS OF HEXAPLOID SOFT WHEAT (Triticum aestivum L.)
}

\section{A.S. RUDAKOVA', S.V. RUDAKOV ${ }^{1}$, N.V. DAVYDOVA ${ }^{2}$, G.V. MIRSKAYA ${ }^{3}$, E.V. ZHURAVLEVA ${ }^{2}$, Yu.V. CHESNOKOV 4}

\author{
${ }^{1}$ State University of Moldova, 60, str. Mateevich, Kishinev, 2009 Moldova; \\ $2_{« N e m c h i n o v k a » M o s c o w}$ Research Institute for Agriculture, Federal Agency of Scientific Organizations, 1, ul. \\ Kalinina, RP Novoivanovskoe, Odintsovo Region, Moscow Province, 143026 Russia; \\ ${ }^{3}$ Agrophysical Research Institute, Federal Agency of Scientific Organizations, 14, Grazhdanskii prosp., St. Peters- \\ burg, 195220 Russia; \\ ${ }^{4}$ Federal Research Center the N.I. Vavilov All-Russian Institute of Plant Genetic Resources, Federal Agency of Scien- \\ tific Organizations, 42-44, ul. Bol'shaya Morskaya, St. Petersburg, 190000 Russia, e-mail yu.chesnokov@vir.nw.ru \\ Acknowledgements: \\ We are grateful to Dr. N.V. Kocherina for help with the statistical calculations of heterozygosity and its dispersion. \\ Received March 25, 2016
}

\section{Abstract}

Esterases represent a large group of enzymes that catalyze cleavage of multiple-ester bonds. In general, they are divided into four types: cholinesterases (most frequently, these are identified using ordinary electrophoretic analysis), acetylesterases, arylesterases and carboxyl esterases. Plant carboxyl esterases catalyze conversion of the esters into bioactive acids and alcohols, thereby playing a key role in many biological processes. Lack of epistatic interactions as well as a co-dominant nature of the inheritance of the esterase isozymes makes them meaningful for quick and accessible investigation of the processes of biochemical adaptation to environmental changes. Such a type of markers, which is convenient for solution of practical problems of selection, can be used as a tool that can speed up and simplify the selection of the significant material. The aim of this study was to estimate the isoenzyme profile of esterases isolated from mature seeds, and to ascertain, using such a biochemical marker, the polymorphism among samples of promising breeding material of the hexaploid wheat (Triticum aestivum L.). Ripe seeds from following wheat cultivars were used as samples: Zlata, Lyubava, Agatha, Lisa (spring wheat) and Mera (winter wheat) (originated by Moscow Agricultural Research Institute «Nemchinovka», Moscow Province); lines AFI91 and AFI177 (spring wheat) and recombinant inbred lines of the mapping populations ITMI - 7, 10, 29, 32, 44, 47, 57, 83, 88, 89, and 115 (spring wheat) (originated by Agrophysical Research Institute - AFI, St. Petersburg). The seeds were ground in a porcelain mortar and the flour was sieved. The enzymes were extracted from the flour and subjected to vertical native electrophoresis using $4 \%$ concentrating and $8 \%$ separating polyacrylamide gels. Molecular weight markers were Page Ruler Prestained Protein Ladder «Thermo Scientific» (Lithuania). After electrophoresis, gels were treated with a reagent for a nonspecific esterase and scanned. Individual electrophoretic profile of each sample was estimated. Heterozygosity and its dispersion were calculated. The esterase complex in the wheat seeds studied was represented by 10 isoforms. From 9 to 10 isoforms of various electrophoretic mobility have been identified in cultivars Zlata, Lyubava, Agatha, Lisa and Mera, 7 isoforms were found in line AFI91, 8 isoforms - in AFI177, and from 7 to 10 isoforms - in ITMI lines. All samples were characterized by the presence of esterases isoforms Est-8, Est-9 and Est-10. Heterogeneity was only found in the qualitative and quantitative composition of esterases with a greater molecular weight - Est-1, Est-2, Est-3, Est-4, Est-5, Est-6, and Est-7. Each variety among eighteen varieties and lines had a genotype different from that in the other samples. The average heterozygosity $(\mathrm{H})$ of samples within 10 loci encoding esterase isoforms was 0.924 ; the dispersion of heterozygosity for all the samples studied was $\operatorname{Var}(\mathrm{H})=0.0004$. As a result of the analyses, following most promising breeding parental forms are varieties Zlata and Mera, and lines AFI91, AFI177, ITMI7, ITMI44, ITMI83, and ITMI115. Because of the existence of ten isoforms in hexaploid wheat, the esterases might represent a convenient biochemical marker suitable for examination of samples of the hexaploid wheat at physiological, biochemical, and genetic levels.

Keywords: hexaploid soft wheat, mature seeds, isozymic analysis, esterase

In breeding, classical phenotypic estimation is becoming less competitive 
with the increasing number of plant genetic resource collections, as it requires time and money, and the results obtained vary when genotype grown under different environmental conditions. Electrophoretic spectrum analysis of polymorphic isozyme markers is less expensive and can be successfully applied for the rapid assessment of plant genotypes, establishing phylogenetic relationships between different species and the identification of genetic drift or other genetic and evolutionary processes at the population level [1-5].

Esterases are a large group of enzymes, at least 20, catalyzing cleavage of ester bonds. In a broad sense, the group includes lipases, phosphatases, sulfatases and actually esterases. The latter integrate numerous specific enzymes: cholinesterase, chlorophyllase, tannase, pectinase, etc. Usually the esterases are divided into four types. Cholinesterases, the most commonly identified in conventional electrophoretic analysis, prefer charged substrates (choline esters of acetic, propionic or butyric acids); acetyl esterases use aliphatic hydrocarbons, in particular acetic acid, as substrates; aryl esterases inhibited by the hydrogen sulfide components, use aromatic hydrocarbons as substrates; carboxyl esterases prefer esters of aliphatic quite long compounds and are inhibited, like cholinesterases, by organophosphorus compounds [6-9].

Plant esterases (EC 3.1.1.X) are a kind of esterases of soybeans, wheat, sorghum, rice and other species $[6,10,11]$. They catalyze the conversion of carboxylic esters to bioactive acids and alcohols, thus playing a key role in many biological processes, such as the activation of signaling molecules [12] and the regulation of the bioactivity of endogenous products [13], including hydrolytic cleavage of ester bonds in pesticides and other xenobiotics [6]. Herbicides Thiazopyr, diclophopmetil and bromoxynil octanoate and fungicide binapacryl are esterase-inactivated [6, 14].

Hexaploid wheat (Triticum aestivum L.) is one of the cultivated species for which the component composition of esterases was studied, but the genetic control of their activity has not yet been fully established. Four blocks are describe for homologous loci controlling esterase in various wheat organs and tissues. Genes for esterase of immature seeds, roots, leaf blades and green leaves are mapped on 3AS, 3BS and 3DS chromosome arms [15-17]. Different specific loci are identified - for etiolated coleoptile esterase on 3AL, 3BL, 3DL, 7BS and 7DS chromosomes [18], for etiolated leaves esterase on 6AL, 6BL and 6DL chromosomes [18-20], and for mature seed esterase on the long arm of chromosomes 3AL, 3BL and 3DL [20-22]. Wheat esterases are described as monomers or dimers $[15,18,19)$.

Lack of epistatic interactions and co-dominant nature of inheritance make esterase isoforms meaningful for quick and accessible study of the biochemical adaptation in plants to changing environment. This type of biochemical markers is also useful in practical breeding as a tool that can speed up and simplify selection of breeding forms.

In this paper, we first reported on the isoenzyme analysis of a number of spring and winter wheat lines and varieties, which made it possible to identify possible parents in breeding Triticum aestivum L. for tolerance and productivity.

Our aim was to evaluate the profile of esterase isozymes from mature seeds in hexaploid wheat, and establish polymorphism between the promising breeding forms on this biochemical marker.

Technnique. Wheat (Triticum aestivum L.) varieties of different origin were used. These were Zlata, Lyubava, Agata, Liza (spring varieties) and Mera (winter variety) (developed in «Nemchinovka» Moscow Research Institute for Agriculture); AFI91 and AFI177 (spring lines) (developed in Agrophysical Research Institute, St. Petersburg), and recombinant inbred spring lines of mapping 
population ITMI $-7,10,29,32,44,47,57,83,88,89$ and 115 (spring).

Seeds were carefully milled in a porcelain mortar, and flour was sieved (a sieve size less than $200 \mu \mathrm{m}$ ). Extraction was carried out at $8-12{ }^{\circ} \mathrm{C}$ overnight with buffer solution that contained $0.005 \mathrm{M}$ Tris- $\mathrm{HCl}(\mathrm{pH} 8.3), 0.001 \mathrm{M}$ $\mathrm{MgCl}_{2}, 10 \%$ glycerol (flour to buffer ratio of 1:2). The extracts were centrifuged for $5 \mathrm{~min}$ at $15000 \mathrm{rev} / \mathrm{min}$, and the supernatant was collected. Then, native vertical electrophoresis was performed [23] with stacking $4 \%$ polyacrylamide gel and separating $8 \%$ polyacrylamide gel in a chamber Mini-PROTEAN Tetra System (Bio-Rad Laboratories, Inc., USA) at $50 \mathrm{~mA} / \mathrm{h}$ and $5-8{ }^{\circ} \mathrm{C}$. Molecular markers were standards Page Ruler Prestained Protein Ladder (Thermo Scientific, Lithuania).

The total loaded volume of protein solution (without dyes and other agents) was 10-15 $\mu \mathrm{l}$ per lane. After electrophoresis was complete the gel was treated with a reagent for nonspecific esterase. For this the gel was 5-10 min exposed to freshly prepared dye solution until brown coloring appeared. The dye solution was prepared as follows: $0.1 \mathrm{~g}$ of 1-Naphthyl Acetate (Sigma-Aldrich, Switzerland) was dissolved in $5 \mathrm{ml}$ of $70 \%$ ethanol, then slowly poured with stirring in $15 \mathrm{ml}$ of $0.1 \mathrm{M}$ phosphate buffer ( $\mathrm{pH} \mathrm{6.0)}$ ). Then, $0.25 \mathrm{~g}$ of Fast Blue RR (Aldrich, USA) was dissolved in $4 \mathrm{ml}$ of propanol and $15 \mathrm{ml}$ of $0.1 \mathrm{M}$ phosphate buffer ( $\mathrm{pH}$ 6.0). Both solutions were mixed (1:1), filtered through pleated paper and immediately used for visualization of esterase activity bands [24]. After the bands became dark, the excess dye was removed by washing the gel with $7 \%$ acetic acid.

The resulting electropherograms were scanned on an Epson Expression 10000 XL (GE Healthcare, USA). Individual electrophoretic profile of each sample was evaluated using Phoretix 1D program (TotalLab, Ltd., UK).

Heterozygosity and its variance were calculated according to M. Nei [25] and B. Weir [26] based on earlier described algorithms for quantifying polymorphism level [27]

Results. Development and description of the mapping population ITMI lines have been published previously [28-30]. Description and characterization of the varieties Zlata, Lyubava, Agata, Liza and MEra are given in the relevant databases of the State Register of the Russian Federation.

AFI91 line was obtained by individual selection in crossing varieties Asakaze komugi (spring wheat) $\times$ Leningradskaya rannyaya. The line is early ripening, stunted, semi-beard, o erectoid plant type, long and narrow leaf blade, pyramidal ear, which is moderately tightly-packed, with middle length and low grain number per ear. Grain weight per ear varies from low to middle; grains are small in size, elongated in shape and red-colored. AFI177 line was developed by individual selection in crossing Asakaze komugi $\times$ Sonora 64. The line is early ripening, semi-dwarf semi-beard, with inclined plant type, leaf blade middlesized in length and in width, pyramidal ear, which is moderately tightly-packed, with middle length and middle grain number per ear. Grain weight per ear varies from low to middle; grains are small in size and red-colored.

Esterase complex in the studied wheat seeds consisted of 10 isoforms (Fig.). In varieties Zlata, Lyubava, Agata, Liza and Mera there were from 9 to 10 isoforms of different electrophoretic mobility. Similar electrophoretic patterns were found in varieties Agata and Liza Est-2 activity was more expressed.

We have found 7 isoforms in AFI91, 8 isoforms in AFI177, and form 7 to 10 isoforms in ITMI lines. Isozyme patterns of ITMI lines differred from each other. Only in ITMI10 and ITMI29 lines the patterns were similar both in qualitatively and quantitatively, being different from AFI91 and AFI177 patterns and the isozyme patterns of all the studied varieties, so they can be used for analysis 
in crosses with any of the tested varieties or lines AFI91 and AFI177.

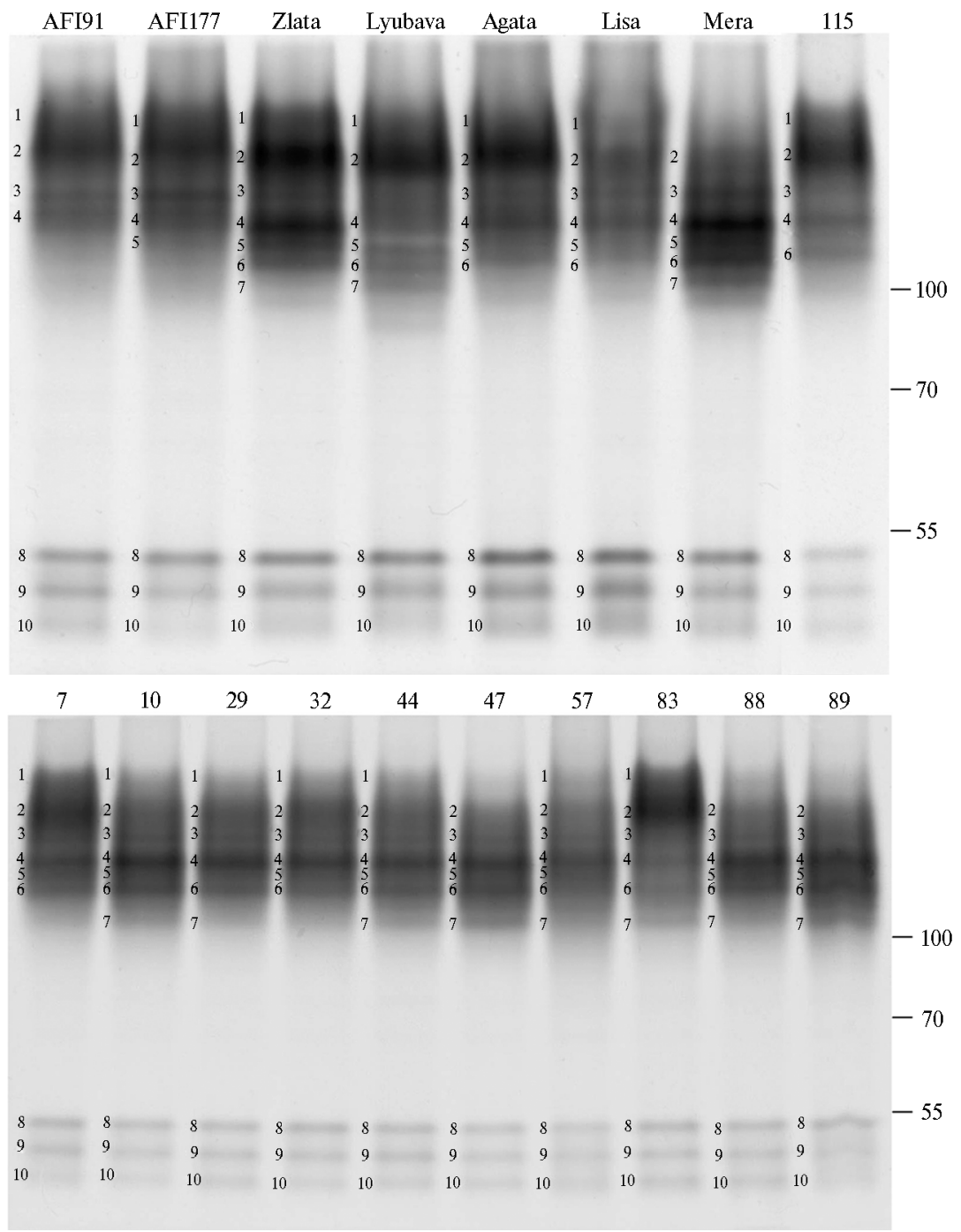

Electrophoretic patterns of esterase isoforms in studied hexaploid soft wheat (Triticum aestivum L.) varieties and recombinant inbred lines from mapping population ITMI. Molecular weight markers $(\mathrm{kDa})$ are on the right. Esterase isoforms are numbered along the tracks.

The presence of isoforms Est-8, 9 and Est-Est-10 were characteristic of all the samples. Qualitative and quantitative heterogeneity was only mentioned in the esterases of a greater molecular weight - Est-1, Est-2, Est-3, Est-4, Est-5, Est-6 and Est-7.

Est-2 and Est-4 were detected in all studied samples, though Est-2 activity was higher in varieties Zlata, Lyubava, Agata and lines ITMI7, ITMI83, ITMI115, while Est-4 activity was higher in varieties Zlata, Mera and lines ITMI10, ITMI29, ITMI32, ITMI44, ITMI47, ITMI88, ITMI89. Est-6 isoform was found in all the evaluated varieties and ITMI lines except lines AFI91 and AFI177. The maximum activity of Est- 6 was detected in variety Mera and line ITMI89, and in the rest varieties and lines ITMI it ranged from low to moderate. Est-1 was detected in al the samples except variety Mera and lines ITMI47, ITMI88 and ITMI89. Est-7 presented in varieties Zlata, Lyubava, Mera and lines ITMI10, ITMI29, ITMI44, ITMI47, ITMI57, ITMI83 and ITMI89. Est-3 was found in all the samples except Lyubava, with the highest activity in the variety 
Mera. Est-5 was absent only in lines AFI91, ITMI29, ITMI83 and ITMI115, with the highest activity found in varieties Zlata, Mera and line ITMI89.

Interestingly, variety Mera which possessed nine of the ten esterase isoforms was the only winter one among the studied samples. In this, the activity of an average molecular weight isoforms was higher than that of low and high molecular weight isoforms. That is the variety Mera can be used as the parent form in crossing with any samples estimated on esterase patterns. Lines AFI91 and AFI177 can also serve as parental forms in crosses with each other or with the other studied lines and varieties.

Zlata and and Lyubava possessed a unique range of electrophoretic esterase isoforms. Est-3 and higher activity Est-4 were characteristic of variety Zlata, unlike the variety Liubava. Varieties Agata and Liza were characterized by similar esterase patterns, though Agata had a higher activity of Est-2. ITMI lines had similar esterase profiles, however, differed from each other and from AFI91 and AFI177, as well as from all the varieties tested. Lines ITMI7, ITMI83, ITMI89 and ITMI115 were clearly distinct on morphological parameters [30], which allows their use in crossing.

Genotypes of 18 studied varieties and lines were specifically distinct from each other. We estimated their heterozygosity for 10 identified loci encoding esterase isoforms. The average heterozygosity $\mathrm{H}$ was 0.924 with heterozygosity variance for the studied sample set $\operatorname{Var}(\mathrm{H})=0.0004$.

Because the sample size was relatively small, and there were only 5 polymorphic esterase isoforms, for the calculation of heterozygosity we used an approach proposed by M. Nei [25] and B. Weir [26], which allows for more accurate estimation of the average heterozygosity and its variance. Revealed heterozygosity was regarded as the average portion of loci with two distinct alleles per locus in a single individual and could be determined as the observed heterozygosity characterizing the part of genes for which the population is heterozygous [27]. The main difference of the statistical approaches we used was that the authors $[25,26]$ brought uniformly proportioned minimum deviation of an unbiased estimator of heterozygosity $(\mathrm{H})$ in accordance with its exact variance value $\operatorname{Var}(\mathrm{H})$. To this end, they got the formula allowing to calculate any polynomial in the set of variables, distributed multinomially, which makes it possible to consider a detectable heterozygosity as a measure of information polymorphism, being an important component in planning breeding programs and one of the key indicators of their performance. However, the detection of any breeding traits depends on the genotype of the samples, and consequently, the information polymorphism is nothing but a reflection of phenotypically and(or) biochemically revealed activity and genome-wide distribution of genetic determinants (genes, chromosome loci) determining the expression of these traits.

Previously, it was shown that the genes encoding esterase isoforms are located on chromosome 3 of the all three genomes of hexaploid wheat [20-22]. From this, differentiation of that part of the genomes occurred during the evolution. We can assume at least two mutational events that influenced the distribution of genes encoding esterase isoforms among homologous chromosomes. This can also be applicable to hybrid isoenzyme forms (dimers, trimers or tetramers, etc.), since these forms can occur only due to the presence of various polymers in plant tissues and organs $[15,18,19]$. The fact that the identified isoenzymes are encoded by homeologous chromosomes (and possibly their arms) is consistent with the hypothesis about a relatively recent differentiation of A, B and D genomes in wheat [21]. The transition from tetraploid to hexaploid forms confirmed by additivity of esterase isoforms leads to generalizing conclusion about the possibility of using the system of esterase isoforms to increase the plasticity 
of polyploids and their adaptation to different environmental conditions. This is consistent with the observation that polyploids better able to colonize areas compared with closely related diploid species $(3,6]$.

Thus, our results disclose the most perspective parent forms among studied wheat varieties and lines. These are Zlata and Mera, and AFI91, AFI177, ITMI7, ITMI44, ITMI83 and ITMI115, which differ not only in phenology and phenotypes but also in the esterase patterns. Moreover, the obtained data on esterase isoforms make it is possible to determine the polymorphism not only in parent forms, but also in the anticipated offspring from crosses. The presence of ten isoforms makes esterases of hexaploid wheat a convenient biochemical marker to be used in physiobiochemical, genetic and breeding research. A more detailed understanding these results will be possible after a comparison of the isozyme patterns in diploid donors of the studied genotypes.

\section{REFERENCES}

1. Boulter D., Thurmann D.A., Turner B.L. The use of disc electrophoresis of plant proteins in systematics. Taxon, 1966, 15: 135-142 (doi: 10.2307/1217532).

2. S h a w C.R. Isozymes: classification, frequency, and significance. Int. Rev. Cytol., 1969, 25: 297-332 (doi: 10.1016/S0074-7696(08)60206-5).

3. H a rt G.E. Genetics and evolution of multilocus isozymes in hexaploid wheat. Isozymes Curr. Top. Biol. Med. Res., 1983, 10: 365-380.

4. B row n A.H., Clegg M.T. Isozyme assessment of plant genetic resources. Isozymes Curr. Top. Biol. Med. Res., 1983, 11: 285-295.

5. N e vo E. Plant genetic resources: prediction by isozyme markers and ecology. Isozymes Curr. Top. Biol. Med. Res., 1987, 16: 247-267.

6. $\mathrm{Cum} \mathrm{mins} \mathrm{I.,} \mathrm{B} \mathrm{u} \mathrm{r} \mathrm{n} \mathrm{e} \mathrm{t} \mathrm{M.,} \mathrm{Edwa} \mathrm{rds} \mathrm{R.} \mathrm{Biochemical} \mathrm{characterization} \mathrm{of} \mathrm{esterases} \mathrm{active} \mathrm{in}$ hydrolysing xenobiotics in wheat and competing weeds. Physilologia Plantarum, 2001, 113: 477-485.

7. Ca rvalho V.M., M a rques R.M., Lapenta A.S., Machado M.F.P.S. Functional classification of esterases from leaves of Aspidosperma polyneuron M. Arg. (Apocynaceae). Genet. Mol. Biol., 2003, 26(2): 195-198 (doi: 10.1590/S1415-47572003000200013).

8. Hou C.-J., He K., Yang L.-M., Huo D.-Q., Yang M., Huang S., Zhang L., $\mathrm{S}$ h e $\mathrm{n}$ C.-H. Catalytic characteristics of plant-esterase from wheat flour. World J. Microbiol. Biotechnol., 2012, 28: 541-548 (doi: 10.1007/s11274-011-0845-9).

9. Rejon J.D., Zi enki ewicz A., Rodríguez-García M.I., Castro A.J. Profiling and functional classification of esterases in olive (Olea europaea) pollen during germination. Ann. Bot., 2012, 110(5): 1035-1045 (doi: 10.1093/aob/mcs174).

10. G e r shate r M.C., C u m mins I., Edwards R. Role of a carboxylesterase in herbicide bioactivation in Arabidopsis thaliana. J. Biol. Chem., 2007, 282: 21460-21466 (doi: 10.1074/jbc.M701985200).

11. Cu m mins I., Edwards R. Purification and cloning of an esterase from the weed blackgrass (Alopecurus myosuroides), which bioactivates aryloxyphenoxypropionate herbicides. Plant J., 2004, 39: 894-904 (doi: 10.1111/j.1365-313X.2004.02174.x).

12. Stuhlfelder C., Muelle r M.J., Warze cha H. Cloning and expression of a tomato cDNA encoding a methyl jasmonate cleaving esterase. Eur. J. Biochem., 2004, 271: 2976-2983 (doi: 10.1111/j.1432-1033.2004.04227.x).

13. Dogru E., Warzecha H., S eibel F., Ha ebel S., Lottspeich F., Stockigt J. The gene encoding polyneuridine aldehyde esterase of monoterpenoid indole alkaloid biosynthesis in plants is an ortholog of the alpha/betahydrolase super family. Eur. J. Biochem., 2000, 267: 1397-1406 (doi: 10.1046/j.1432-1327.2000.01136.x).

14. Feng P.C.C., Ruff T.G., Kos inski W.G. Metabolic deactivation of the herbicide thiazopyr by animal liver esterases. Xenobiotica, 1995, 25: 27-35 (doi: 10.3109/00498259509061830).

15. B a rber H.N., D ris coll C.J., Vickery R.S. Enzymic markers for wheat and rye chromosomes. In: Proc. $8^{\text {th }}$ Int. Wheat Genet. Symp. Aust. Acad. Sci., Canberra, 1968: 116-122.

16. B a rber H.N., D riscoll C.J., Long P.M., Vickery R.S. Gene similarity of the Triticinae and the study of segmental interchanges. Nature, 1969, 22: 897-898 (doi: 10.1038/222897a0).

17. B e rg m a $\mathrm{n}$ J.W. Chromosome locations of genes controlling esterase and malate dehydrogenase isozymes in Triticum. PhD Diss. North Dakota State University, Fargo, 1972

18. $\mathrm{J}$ a a s k a V. Electrophoretic survey of seedling esterased in wheats in relation to their phylogeny. Theor. Appl. Genet., 1980, 56: 273-284 (doi: 10.1007/BF00282570).

19. M a y C.E., Vi c k e ry R.S., D ri s c o 11 C.S. Gene control in hexaploid wheat. In: Proc. $4^{\text {th }}$ Int. Wheat Genet. Symp. Columbia, 1973: 843-849.

20. N a k a i I. Isoenzyme variations in Aegilops and Triticum. 3. Chromosomal basis of the esterase isozyme production in indifferent organs of Chinese Spring wheat. Bot. Mag., 1976, 89: 219-234 
(doi: 10.1007/BF02488344).

21. Cubadda R., B ozzini A., Quatrucci E. Genetic control of esterases in common wheat. Theor. Appl. Genet., 1975, 45: 290-293 (doi: 10.1007/BF00276681).

22. A insworth C.C., Gale M.D., B a i rd S. The genetic control of grain esterases in hexaploid wheat. Theor. Appl. Genet., 1984, 68: 219-226 (doi: 10.1007/BF00266893).

23. D a v is B.J. Disc electrophoresis. II. Method and application to human serum proteins. Annals of the NY Academy of Sciences, 1964, 121: 404-427 (doi: 10.1111/j.1749-6632.1964.tb14213.x).

24. M e o n S. Protein, esterase and peroxidase patterns of phytophtora isolates from Cocoa in Malaysia. J. Islamic Acad. Sci., 1988, 1(2): 154-158.

25. $\mathrm{Ne} \mathrm{i} \mathrm{M.} \mathrm{Estimation} \mathrm{of} \mathrm{average} \mathrm{heterozygosity} \mathrm{and} \mathrm{genetic} \mathrm{distance} \mathrm{from} \mathrm{a} \mathrm{small} \mathrm{number} \mathrm{of}$ individuals. Genetics, 1978, 89: 583-590.

26. V e i r B. Analiz geneticheskikh dannykh [Genetic data analysis]. Moscow, 1995: 132-135 (in Russ.).

27. Chesnokov Yu.V., Pochepnya N.V., Kozlenko L.V., S itnikov M.N., Mi trofanova O.P., Syukov V.V., Ko chetkov D.V., Lovasser U., B erner A. Vavilovskii zhurnal genetiki $i$ selektsii, 2012, 16(4/2): 970-998 (in Russ.).

28. Ches nok ov Yu.V., Goncharova E.A., Sitnikov M.N., Kocherina N.V., Lovasse r U., B e rne r A. Fiziologiya rastenii, 2014, 61(6): 855-863 (doi: $10.7868 / \mathrm{S} 0015330314060049)$ (in Russ.).

29. Chesnokov Yu.V., Sitnikov M.N., Schumlyanskaya N.V., Kocherina N.V., Goncharova E.A., Kozlenko L.V., Syukov V.V., Kochetkov D.V., Lohwasser U., $\mathrm{B}$ ö $\mathrm{rn}$ e $\mathrm{r}$ A. Catalogue of recombinant inbred lines of mapping population ITMI of soft spring wheat Triticum aestivum L. (ecological and geographical trials and QTL mapping). IPK, VIR, St. Petersburg-Gatersleben, 2014.

30. Chesnokov Yu.V., Artem'eva A.M. Otsenka mery informatsionnogo polimorfizma geneticheskogo raznoobraziya [Evaluation of the measure of polymorphism information of genetic diversity]. Sel'skokhozyaistvennaya Biologiya [Agricultural Biology], 2015, 50(5): 571-578 (doi: 10.15389/agrobiology.2015.5.571eng). 